\title{
Redes e Cooperação na Destinação Turística de Urubici/SC
}

\author{
Networks and Cooperation in the Tourist Destination of Urubici - South Brazil
}

Fabiela Fatima Andrighi ${ }^{1}$

Valmir Emil Hoffmann ${ }^{2}$

\begin{abstract}
Resumo
Este trabalho de caráter descritivo tem como objetivo geral analisar as relações entre os atores pertencentes a uma rede interorganizacional na destinação turística de Urubici. A construção do trabalho tem como alicerce três bases específicas: redes, cooperação e competitividade. De maneira específica são abordadas as relações entre o setor privado, público e entidades relacionados com a atividade turística que utilizam a cooperação para a competitividade dos atores sociais envolvidos, através dos construtos das redes interorganizacionais. O método utilizado foi de cunho descritivo, através de pesquisa bibliográfica de dados secundários, seguida de coleta censitária de dados primários. Não foi possível apontar a existência de rede interorganizacional entre as organizações do turismo local.

Palavras-chave: competitividade; destinação turística, cooperação; redes interorganizacionais.
\end{abstract}

\begin{abstract}
This work of descriptive character has as general objective to analyze the relationships among the actors belonging to an inter-organizational network in the tourist destination of Urubici, South Brazil. The construction of the work has as foundation three specific bases: networks, cooperation and competitiveness. In a specific way the relationships are approached among the private section, public and sector entities related to the tourist activity that they use the cooperation for the involved social actors' competitiveness, through the constructs of the inter-organizational networks. The methodological approach was of descriptive stamp, through bibliographical research of secondary data, followed by survey of primary data. It was not possible to point the existence of inter-organizational network among the organizations of the local tourism.
\end{abstract}

Keywords: competitiveness; tourist destination; cooperation; inter-organizational network.

\footnotetext{
${ }^{1}$ Mestre em Turismo e Hotelaria pela Universidade do Vale do Itajaí; Graduada em Administração de Empresas pela Universidade Comunitária Regional de Chapecó; Professora do Curso de Administração de Empresas da Universidade do Vale do Itajaí. E-mail: fabiela@univali.br.

2 Doutor em Administração pela Universidade de Zaragoza (Espanha); Mestre em Administração pela Universidade Federal de Santa Catarina; Especialista em Marketing; Especialista em Engenharia de Produção; Economista pela Universidade do Vale do Itajaí; Professor Adjunto da Universidade de Brasília do Programa de Pós-Graduação em Administração, Consultor de empresas. E-mail: ehoffmann@unb.br.
} 


\section{Introdução}

A busca pelo incremento da competitividade tem-se constituído em objetivo constante de empresas e governos, e também fator crítico para a prosperidade das firmas, das cidades, das regiões e dos países, inseridos num ambiente de concorrência global (AMATO NETO, 2005). A competitividade se dá pela consecução de vantagem competitiva, que foi definida por Coyne (1986), como sendo a criação de um hiato entre a empresa e seus concorrentes, de modo que o comprador prefira o produto/serviço da empresa, em detrimento daquele de seus concorrentes, ao longo do tempo.

Para compreensão da vantagem competitiva e da adequação à dinâmica da concorrência, almejam-se soluções pelas empresas que objetivam o estabelecimento de outros modelos organizacionais para além da hierarquia e do mercado. Essas novas estruturas empresariais, as redes interorganizacionais, evidenciam os antigos rivais do mercado como potenciais parceiros através de ações de cooperação (BEGNIS; PEDROZO; ESTIVALETE, 2005), na busca por alternativas para a resolução de problemas comuns, o que faz dessa ação uma peça da estratégia competitiva setorial. Esta nova forma de organização das empresas teve início na década de 1980 (THORELLI, 1986), e ainda é difundida e o interesse na pesquisa vem se ampliando. Um estudo em periódicos nacionais mostrou que o tema vem crescendo em termos de publicações, desde o ano 2000, no Brasil e também no exterior (HOFFMANN, ANDRGHI; ANDRADE, 2008).

Neste trabalho foca-se em um tipo particular de rede: aquela que surge no contexto das aglomerações territoriais. Diversas abordagens teóricas sobre o tema redes oferecem uma vasta base e um potencial diálogo entre os vários ramos das ciências sociais aplicadas. No campo organizacional, há crescente interesse nesse tema devido ao seu potencial de sustentar o desenvolvimento e a competitividade das empresas e/ou regiões (LORENZONI; ORNATI, 1988; BRUSCO; RIGHI, 1989; BALESTRIN; VARGAS, 2004). Ou seja, como observado nos estudos realizados por Porter (1992), a concentração geográfica de empresas está vinculada às vantagens competitivas.

O trabalho de Marshall (1925), que pode ser considerado o precursor das discussões acerca das aglomerações territoriais, indica ganhos de eficiência associados ao agrupamento setorial e regional de empresas. O turismo se beneficia dessa abordagem, pois a grande maioria dos 
destinos turísticos são aglomerações de empresas, em um processo de complementaridade como pode ser a hotelaria, o transporte e a alimentação, e com ênfase em pequenas empresas (O'CONNOR, 2001). Nesses ambientes é possível estabelecer algum tipo de cooperação entre concorrentes, com vistas aos objetivos comuns da destinação, como a criação de um convention bureau para atrair eventos para o destino. E a competitividade se liga à cooperação, pois Pyke; Becattini; Sengenberger (1990) e Saxenian (1995) apontam para os fortes ganhos de competitividade com a criação de redes de cooperação de empresas, nas regiões, respectivamente, da Terceira Itália e do Vale do Silício, nos Estados Unidos. No turismo, segundo Tremblay (1998), as redes interorganizacionais realizam a ligação entre as potencialidades individuais encontradas nos destinos turísticos e tornam a concorrência uma competição sadia, na busca pela competitividade dos atores envolvidos e da destinação turística. Em contextos de aglomeração territorial, como as destinações turísticas, as pequenas empresas tendem a alcançar ganhos maiores, pela ação cooperada, que aqueles que seriam possíveis pela atividade isolada, conforme Mottiar; Tucker (2007). Essa cooperação não suprime a competição. Ou seja, no âmbito intra-regional (dentro da destinação), as empresas permanecem competindo umas contra as outras em termos de turistas para a hotelaria ou a restauração, mas no âmbito inter-regional, essas mesmas empresas vão cooperar, para alcançar vantagem competitiva contra outras destinações (MOTTIAR; TUCKER, 2007).

Assim, enquanto se constata a importância da organização em redes para aumentar a competitividade e promover o desenvolvimento de um determinado local ou região, também se verifica, segundo Schuch (2001), que o setor turístico encara os mesmos desafios dos setores industriais, com empresas fragmentadas, com comprometimento e limitação do seu potencial de crescimento no mercado (BENI, 2004). Junte-se a isso o fato de a baixa competitividade comprometer o sistema turístico como um todo (SWARBROOKE, 2000). Assim, ao estudar as redes no turismo também se estará entendendo, ao que parece, a competitividade de uma destinação. O turismo conta com uma estrutura econômica própria através de diversas organizações intermediárias que promovem e realizam a distribuição do produto turístico, tornando complexo o gerenciamento desta atividade. A estruturação e as características do turismo como setor oferecem noções para a aplicação dos estudos das redes interorganizacionais (NORDIN, 2005). 
Considerando o potencial do turismo e as pesquisas sobre redes interorganizacionais desenvolvidas até o momento, que apresentam resultados vinculados às vantagens competitivas, julga-se relevante analisar as relações entre os atores pertencentes a uma rede interorganizacional, com enfoque na cooperação, e suas contribuições para a competitividade dos atores turísticos da destinação Urubici, que é uma destinação turística recente e em expansão, em termos de turismo de inverno em Santa Catarina. Este trabalho está estruturado em cinco partes: introdução; fundamentação teórica; a metodologia utilizada; a análise dos resultados a conclusão dos resultados e as limitações do estudo e os direcionamentos para futuros trabalhos sobre o tema.

\section{Fundamentação}

No final do século XX, Porter (1999) já escrevia que a competição havia se intensificado nos últimos anos em todos os setores e praticamente em todas as partes do mundo, tornando premente a necessidade de as organizações se manterem competitivas. Isso também foi constatado mais tarde, quando Wegner; Dahmer (2004) escreveram que a modificação dos padrões de competição trouxe uma nova realidade para as empresas, indústrias, países e regiões independentemente do seu tamanho e localização.

Sabe-se que as organizações encontram dificuldades para competir no mercado, não propriamente devido ao seu tamanho, mas porque agem isoladas (FERNANDES, 2005), o que as levam a enfrentar problemas na gestão do seu negócio: mais custos, menos tecnologia, inovação e visibilidade no mercado. Conseqüentemente, não conquistam vantagens competitivas. A partir dessa constatação, emergem novos modelos de estruturas organizacionais, como as redes, aglomerações (clusters), cadeias de suprimento, arranjos produtivos locais, visando a construção de estratégias eficazes para as organizações. Essas novas estruturas organizacionais partem do princípio de que, no atual ambiente de negócios, nenhuma empresa, seja ela pequena ou grande, pode ser independente e auto-suficiente (WITTMANN; NEGRINI; VENTURINI, 2003), sem que isso reflita em seus custos. E todas têm de se adequar às novas características do ambiente e ser mais competitivas (WITTMANN; NEGRINI; VENTURINI, 2003). 
Em termos de redes, Jarillo (1988) descreve que elas são acordos de longo prazo que definem objetivos comuns, para a obtenção de vantagens competitivas frente aos concorrentes, e Hall (2001, p.233) corrobora afirmando que são articulações de "cooperação e colaboração entre empresas". Já no conceito de Powell (1990), as redes são o caminho intermediário entre as estruturas competitivas de mercado, a posição individual ocupada pela empresa e as hierarquias presentes nas relações entre as partes. Gulati; Nohria; Zaheer (2000) entendem rede interorganizacional como um conjunto de relacionamentos de forma vertical e horizontal com outras organizações, sejam elas fornecedores, clientes, concorrentes e entidades públicas ou privadas.

Como afirma Verschoore Filho (2003), as redes interorganizacionais têm como propósito central reunir em uma única estrutura as características essenciais ao novo ambiente competitivo, sustentada por uma governança altamente descentralizada, o que evita que as organizações envolvidas percam a flexibilidade e a agilidade. Quanto às motivações para a formação de rede interorganizacional, Hoffmann et al. (2004, p.03) fazem referência a fatores como "a complexidade de produtos, a troca de conhecimento, aprendizagem organizacional e disseminação de informação; demanda por rapidez de resposta; confiança e cooperação; e defesa contra a incerteza". Erbers; Jarillo (1998) descrevem a rede interorganizacional como uma conseqüência de vínculos constantes entre um grupo de organizações - empresas, sindicatos, associações, órgãos públicos - que atuam para um mesmo mercado e no qual há ligação entre fornecedores e compradores, com o objetivo de compartilhar atividades e relações informais. No turismo, as redes interorganizacionais "são consideradas associações formadas por diferentes agentes produtivos, localizados em um mesmo território, voltadas para a construção de estratégias cooperadas de inserção do território na economia nacional" (VALE, 2004, p. 07).

Neste estudo, redes interorganizacionais são entendidas como processos de interação entre atores sociais públicos e privados autônomos e interdependentes, que cooperam porque têm objetivos comuns (COSTA, 2005). Este conceito foi estruturado com referencial nos construtos de cooperação, confiança, ações integradas e relações de reciprocidade, como fatores de competitividade (JARILLO, 1988; ANDION, 2003a, 2003b; PAVLOVICH, 2003).

As primeiras considerações a respeito das vantagens da concentração de empresas e da eficiência coletiva remontam aos estudos do economista inglês Alfred Marshall (1925), 
desenvolvidas no início do século passado. Para aquele autor, a concentração de organizações em uma determinada localidade pode gerar ganhos de escala transformando a economia de uma região. Para Lastres; Cassiolato (2003), a aglomeração de empresas, e o aproveitamento das sinergias coletivas geradas por suas interações e destas com o ambiente onde se localizam vêm efetivamente fortalecendo as chances de sobrevivência e crescimento das empresas, constituindo-se em importante fonte geradora de vantagens competitivas duradouras. Corroborando, Woitchunas; Sausen (2005) consideram o grau de articulação e cooperação entre as instituições, pessoas, governos e demais atores da sociedade, que dão origem às estruturas de redes interorganizacionais, capazes de aumentar as forças regionais para competir no mundo globalizado.

Em iniciativas no setor turístico, acredita-se que o envolvimento interorganizacional conduz a maior sustentabilidade dos projetos e ações, para a potencialização dos recursos disponíveis e o melhor posicionamento competitivo das cidades e regiões, o que possibilita o desenvolvimento e o crescimento das economias locais e regionais (VASQUEZBARQUERO, 2002). Cabe ressaltar que para o alcance desses possíveis benefícios são necessárias algumas condições, entre elas a cooperação, que pode realizar transformações importantes nas organizações participantes, e mudar as percepções sobre competição, o que possibilita considerar os concorrentes como parceiros (POWELL, 1990), além de ser foco para o desenvolvimento da competitividade interorganizacional (VERSCHOORE FILHO, 2003). No Brasil, contudo, a pesquisa aponta que a cooperação é minimizada, pois segundo Meyer-Stamer (1999, p.13), “a falta de articulação política do setor privado é uma das características mais notáveis da organização do Estado brasileiro". Além disso, considerandose o setor turístico, exige-se um esforço adicional para se compreender estratégias corporativas, e a importância da aglomeração territorial para a construção de vantagens competitivas (COSTA, 2005) e atenção às formas organizacionais das empresas. É sabido que a confiança é uma função do tempo, conforme Williamson (1991). O conhecimento entre as partes gera confiança, pela minimização da expectativa de oportunismo. Com base na confiança, pode-se estabelecer relacionamentos que são mais baratos, pois não demandam contratos (WILLIAMSON, 1991). Nas destinações turísticas, o efeito da aglomeração pode auxiliar o estabelecimento da confiança, ainda que isso não ocorra em todas as localidades (MOTTIAR; TUCKER, 2007). 
Outra condição determinante na capacidade de articulação dos componentes das redes interorganizacionais e, conseqüentemente, para o seu desempenho é a comunicação (CASTELLS, 1999). Relacionamento com base em confiança, troca de informações (comunicação) e ações coletivas, são aspectos que normalmente estão relacionados à cooperação interorganizacional (KNORRINGA; MEYER-STAMER, 1998).

\section{Metodologia}

O trabalho apresenta caráter descritivo. O estudo se pautou na percepção dos envolvidos com o turismo na cidade de Urubici, sobre a evolução das relações de cooperação, confiança e comunicação no período 2001 a 2006. A coleta de dados foi censitária e foi composta de duas etapas: levantamento de dados secundários em sítios eletrônicos oficiais e documentos da cidade e a segunda com a aplicação de um questionário com perguntas fechadas, previamente elaborado por Hoffmann (2002) e modificado e utilizado por Costa (2005), junto aos componentes do universo de pesquisa: os atores sociais representativos do setor público, setor privado e entidades, representados por seus gestores, atingindo 49 respondentes dos 54 possíveis. Considerando a grande disparidade entre o número de atores de cada setor (3 entidades, 6 poder público e 40 poder privado), e também porque as entidades apresentaram constantemente um desvio padrão elevado, o que poderia proporcionar um viés na análise dos resultados, optou-se em agrupar as entrevistas do setor público com as entidades. Desta forma, os resultados analisados foram de dois grupos: setor privado e setor público e entidades. Isto foi possível, pois os resultados individuais desses dois últimos grupos apresentaram um desvio padrão menor que aquele observado na comparação com o grupo das empresas.

No tratamento, foram aplicadas técnicas estatísticas de análise descritivas e de associação com suporte operacional do software estatístico Statistica 6.0. Como medidas descritivas de dados quantitativos, foram empregadas a média e o desvio padrão, complementados pelas medidas de associação para análise das variáveis nominais. Para as variáveis intervalares, escala continua de 7 pontos e extremos bipolares de concordância (Quadro 1), foram aplicadas na análise medidas paramétricas de contraste, a fim de possibilitar a análise comparativa entre os setores e verificar a significância das diferenças entre as médias. 


\begin{tabular}{|l|c|}
\hline \multicolumn{1}{|c|}{ Médias } & Interpretação \\
\hline De 1,0 a 3,9 & Viés à baixa concordância \\
\hline De 4 a 4,9 & Sem viés de medida \\
\hline De 5,0 a 7,0 & Viés de alta concordância \\
\hline
\end{tabular}

Quadro 1 - Interpretação da escala continua de 7 pontos

Fonte: elaboração própria

\section{Resultados}

Estes resultados discutem as variáveis das relações em redes: cooperação, a confiança e a comunicação percebidas pelos atores entrevistados.

A compreensão da condição da rede interorganizacional consiste em um primeiro passo para o estudo da competitividade das demais redes de destinações turísticas. Nesse sentido, a cidade de Urubici, localizada nos aparados da Serra Geral, na região sul do Planalto Catarinense é alvo do desenvolvimento desta pesquisa, que pode ser considerada oportuna, dada a escassez de estudos voltados a esta temática inserida no contexto turístico relacionado ao econômico e social. Pertencente à Microrregião dos Campos de Lages, Urubici tem um potencial turístico representado por atrativos diferenciados (SANTUR, 2006), possui uma área geográfica de $1.019 \mathrm{Km}^{2}$ (IBGE, 2007), que permite estimar que as relações sociais são visíveis, pois elas são mais comuns em localidades onde há concentração de empresas de um mesmo setor, também no turismo (MOTTIAR; TUCKER, 2007). Também os crescentes investimentos neste setor no município e, principalmente, pela aglomeração geográfica de empresas turísticas, são indícios para a existência de rede interorganizacional.

\subsection{Cooperação, confiança e comunicação}

A cerca da cooperação entre as empresas privadas do turismo local, o poder público e as entidades perceberam a maior média $(5,78)$, enquanto o setor privado percebe uma média menor $(4,39)$. Em seguida, figurou a cooperação entre as empresas privadas do turismo local e o governo, novamente o poder privado foi o que apresentou a menor média $(3,97)$. A cooperação entre os sindicatos/associações e empresas privadas do turismo local foi percebida 
com maior intensidade pelo poder público e as entidades $(5,12)$. A cooperação entre as instituições de pesquisa/ensino e as empresas privadas do turismo local foi percebida com menos intensidade que as demais $(4,02)$, principalmente pelo setor privado $(3,79)$. Observando estes dados (Tabela 01), a cooperação entre os atores sociais apresentou médias concentradas no valor 4 .

Tabela 1 - Freqüência e média da cooperação percebida entre os atores sociais do turismo local por setor

\begin{tabular}{l|l|c|c}
\hline & Tipo de Organização & Freqüência & Média \\
\hline \multirow{2}{*}{$\begin{array}{l}\text { Existe cooperação entre as empresas } \\
\text { turisticas privadas }\end{array}$} & Poder Público e Entidades & 9 & 5,78 \\
\cline { 2 - 4 } & Poder Privado & 38 & 4,39 \\
\cline { 2 - 4 } & Total & 47 & 4,66 \\
\hline \multirow{2}{*}{$\begin{array}{l}\text { Existe cooperação entre as empresas } \\
\text { turisticas locais e o governo }\end{array}$} & Poder Público e Entidades & 8 & 5,75 \\
\cline { 2 - 4 } & Poder Privado & 38 & 3,97 \\
\cline { 2 - 4 } & Total & 46 & 4,28 \\
\hline \multirow{2}{*}{$\begin{array}{l}\text { Existe cooperação entre as empresas } \\
\text { turisticas locais e os sindicatos/associações }\end{array}$} & Poder Público e Entidades & 8 & 5,12 \\
\cline { 2 - 4 } & Poder Privado & 39 & 3,87 \\
\cline { 2 - 4 } & Total & 47 & 4,08 \\
\hline $\begin{array}{l}\text { Existe cooperação entre as empresas } \\
\text { turisticas locais e as instituições de } \\
\text { pesquisa/ensino }\end{array}$ & Poder Público e Entidades & 8 & 5,12 \\
\cline { 2 - 4 } & Poder Privado & 39 & 3,79 \\
\hline
\end{tabular}

Fonte: elaboração própria a partir da pesquisa de campo

Além de questionados sobre os parceiros, e a fim de compreender as ações cooperativas desenvolvidas no município de Urubici referentes ao turismo local, os entrevistados foram indagados sobre a freqüência com que realizam ações cooperativas conjuntas (Tabela 02), consideradas pela literatura como fonte de vantagens competitivas (PORTER, 1992; SENGENBERGER; PYKE, 1992). Analisando de maneira agregada, o setor público e as entidades e o setor privado tendem a indicar realização, pois na Tabela 02, nota-se que os encontros periódicos e a divulgação conjunta são as ações cooperativas que apresentaram médias com viés de alta concordância, próximos da divulgação conjunta da destinação, conforme as organizações do turismo local sob estudo. 


\begin{tabular}{|l|l|c|r|}
\hline \multicolumn{4}{|c|}{ Tabela 2 - Freqüencia e médias das ações cooperativas por tipo de organização } \\
\hline Ações Cooperativas & Tipo de Organização & Freqüência & Média \\
\hline \multirow{2}{*}{ Encontros periódicos } & Poder Público e Entidades & 2 & 5,11 \\
\cline { 2 - 4 } & Poder Privado & 39 & 4,44 \\
\hline \multirow{2}{*}{ Divulgação conjunta } & Poder Público e Entidades & 2 & 5,22 \\
\cline { 2 - 4 } & Poder Privado & 40 & 4,12 \\
\hline \multirow{2}{*}{ Compras e vendas conjuntas } & Poder Público e Entidades & 8 & 2,12 \\
\cline { 2 - 4 } & Poder Privado & 39 & 1,69 \\
\hline \multirow{2}{*}{ Eventos conjuntos } & Poder Público e Entidades & 2 & 3,33 \\
\cline { 2 - 4 } & Poder Privado & 39 & 2,95 \\
\hline \multirow{2}{*}{ Treinamentos conjuntos } & Poder Público e Entidades & 2 & 4,55 \\
\cline { 2 - 4 } & Poder Privado & 39 & 2,79 \\
\hline \multirow{2}{*}{ Implantação conjunta de projetos } & Poder Público e Entidades & 9 & 3,55 \\
\cline { 2 - 4 } & Poder Privado & 40 & 2,70 \\
\hline \multirow{2}{*}{ Decisões de longo prazo conjuntas } & Poder Público e Entidades & 9 & 3,77 \\
\cline { 2 - 4 } & Poder Privado & 40 & 2,42 \\
\hline \multirow{2}{*}{ Fonte: elaboração própria a partir da pesquisa de campo } & & \\
\hline
\end{tabular}

Quando questionados a respeito da manutenção da cooperação entre a empresa e as demais organizações turísticas locais (OTL), no período de 2001 a 2006, tomando os setores de maneira agregada, $58 \%$ dos respondentes percebem que a cooperação entre sua organização e as demais organizações turísticas locais aumentou. Entre os respondentes, o poder privado (23) é o que mais afirma ter aumentado a cooperação com as organizações turísticas locais no período de 2001 a 2006. Assim, as médias da participação dos respondentes em ações cooperativas mostram viés de alta concordância à percepção da cooperação entre os atores do turismo e do desempenho da cooperação no período de 2001 a 2006.

No que diz respeito à confiança, os respondentes foram questionados de três formas: de maneira mais geral, se as organizações do turismo local demonstram confiança umas nas outras, de maneira mais específica, se a pessoa respondente (enquanto gestor de uma organização) realiza negócios apenas com base em confiança e, buscando uma compreensão longitudinal, como se deu a evolução da confiança entre as organizações do turismo no período de 2001 a 2006.

A análise agregada dos setores mostra que os respondentes observam pouca demonstração de confiança entre as organizações do turismo local de Urubici/SC (3,98 com desvio padrão de 1,94) (Tabela 03). Quando questionadas sobre a realização de negócios apenas com base em confiança, a média de percepção apresenta em viés de medida (4,54 com desvio padrão de 
2,00), ou seja, as organizações do turismo local apontam um baixo índice de realização de negócios com base em confiança.

\begin{tabular}{|c|c|c|c|}
\hline & Tipo de Organização & Freqüência & Média \\
\hline \multirow{3}{*}{$\begin{array}{l}\text { As OTL demonstram confiança umas nas } \\
\text { outras }\end{array}$} & Poder Público e Entidades & 9 & 4,55 \\
\hline & Poder Privado & 38 & 3,85 \\
\hline & Total & 48 & 3,98 \\
\hline \multirow{3}{*}{$\begin{array}{l}\text { Faço negócios apenas com base em } \\
\text { confiança }\end{array}$} & Poder Público e Entidades & 8 & 2,87 \\
\hline & Poder Privado & 40 & 4,88 \\
\hline & Total & 48 & 4,54 \\
\hline
\end{tabular}

Sobre a evolução da percepção da confiança nos setores no período de 2001 a 2006, inversamente ao observado nas duas questões apresentadas anteriormente sobre confiança, $64,58 \%$ dos respondentes indicam a percepção no aumento da confiança entre a empresa e as demais organizações do turismo local, no período em estudo.

Os respondentes percebem $(54,17 \%)$ que a comunicação da sua empresa com as demais organizações do turismo local aumentou, no período de 2001 a 2006. A maioria das respostas ficou concentrada na categoria viés de alta concordância, o que demonstra o aumento da comunicação entre as organizações do turismo de Urubici, no período de 2001 a 2006, percebido pelos setores sob estudo. Essa tendência geral mostra também que a evolução da confiança entre os entrevistados em ambos os setores teve comportamento semelhante à comunicação nos últimos cinco anos. Desta forma, calculando-se a associação entre essas variáveis com o teste do qui-quadrado, percebe-se uma associação entre confiança e comunicação $(p=0,00)$. A literatura indica relação entre confiança e comunicação, como base para a potencialização das virtudes da cooperação nas relações interorganizacionais (SCHOMMER, 2001), que podem ser figuradas por ações coletivas, determinantes para o desenvolvimento da cooperação.

Ainda que a confiança e a comunicação sejam mais percebidas, verificou-se que essas ações, aqui entendidas como treinamentos, divulgação, compras/vendas, eventos, implantação de projetos e decisões em longo prazo para o turismo local, em conjunto, foram realizadas com 
viés à baixa concordância em ambos os setores, na população sob estudo. A literatura aponta que as organizações que compartilham esses aspectos da cooperação a reforçam, e também robustecem o surgimento de redes interorganizacionais (SILVA, SCHROEDER, HOFFMANN, 2004). Comparando os setores, percebe-se que o setor privado registrou menor freqüência de ações cooperativas, ainda que identifique maiores freqüências de confiança e comunicação. Talvez isso aponte para o fato de que a cooperação seja uma etapa de relacionamento posterior e que a confiança e a comunicação seriam condições prévias para que haja cooperação. No texto de Mottiar; Tucker (2007) evidencia-se que a comunicação entre as empresas se desenvolve a partir de uma associação criada para desenvolver uma das localidades estudadas.

\section{Considerações Finais}

No turismo, as redes interorganizacionais são consideradas um incremento nas potencialidades individuais, para desenvolver vantagem competitiva no âmbito coletivo da destinação (MOTTIAR; TUCKER, 2007). No caso deste estudo, foram analisadas as relações entre os atores pertencentes a uma rede interorganizacional na destinação turística de Urubici/SC. Ao estudar a variável cooperação, os resultados indicam sem viés de medida entre as organizações do turismo local e com viés à baixa concordância para as ações cooperativas. Foi possível apontar que, a menor freqüência de ações cooperativas entre as empresas turísticas locais, em contrapartida, foi o grupo que mais percebeu o aumento da confiança no período.

De forma agregada, os atores do turismo de Urubici perceberam a variável confiança com viés à baixa concordância. A confiança é vista pela literatura como uma condição necessária e base para a formação de redes interorganizacionais (JARILLO, 1988; POWELL, 1990; AMATO NETO, 2000; HALL, 2001). Em contrapartida, 64,58\% indicaram aumento da confiança entre as organizações do turismo local, no período de 2001 a 2006, o que reforça a idéia de uma rede interorganizacional em fase inicial de construção. Além disso, as organizações perceberam o aumento da comunicação no período em estudo, sendo o setor privado foi o que menos percebeu o desempenho da comunicação nesse período. Como evidenciado pela literatura, a cooperação compartilha informações gerando novas idéias e o desenvolvimento 
para explorá-las (FILOS; BANAHAN, 2000). A relação entre as organizações do turismo de Urubici não apresentou indícios suficientes para supor a existência de uma rede interorganizacional, mesmo assim foi identificada a percepção sobre a competitividade dos atores da destinação em estudo. Infere-se assim, que a aglomeração territorial, típica das destinações turística não é uma condição suficiente para a existência de uma rede interorganizacional.

Pôde-se perceber que Urubici se situa em um estágio preliminar à constituição de uma rede, pois apresentou aumento da cooperação, confiança e comunicação entre as organizações do turismo local no período investigado de 2001 a 2006. Por ser uma destinação aglomerada geograficamente e por possuir aspectos ligados à construção de redes interorganizacionais, pode-se pensar que se esse incremento continuar, com o passar do tempo, outras pesquisas poderão apontar a existência de uma rede consolidada na destinação turística de Urubici. Deve ser ponderado ainda que Urubici é uma destinação turística recente. É possível inferir que esse ponto também influencie a construção da rede. Como a confiança vincula-se ao tempo de existência das relações (WILLIAMSON, 1991), é possível que ainda não tenha transcorrido tempo suficiente para que um grande número de transações tenham existido entre as partes e assim, mitiga-se a confiança.

Este trabalho está limitado pela a diferença de respondentes entre o setor público e as entidades e setor privado, o que não permitiu o uso de testes estatísticos mais robustos; pela utilização dos dados agregando os setores em estudo. Como propostas para estudos futuros, sugerem-se trabalhos que busquem avaliar os motivos que influenciam a relação entre os atores sociais desta destinação, comparem esta e outras destinações turísticas, com uma abordagem qualitativa. Indica-se também a aplicação desse tipo de trabalho a outras destinações turísticas, o que pode permitir no futuro, um exercício de comparação entre localidades.

\section{Referências}

AMATO NETO, J. 2000. Redes de cooperação produtiva e cluster regionais: oportunidades para as pequenas e médias empresas. São Paulo: Atlas.

2005. Redes dinâmicas de cooperação e organizações virtuais. Redes entre Organizações. p. 68-93, São Paulo: Atlas, 2005. 
ANDION, C. 2003a. Análise de Redes e Desenvolvimento Local Sustentável. Revista de Administração Pública, vol. 37, n.5, p. 1033-54, set-out.

2003b. O papel das Redes na Promoção do Desenvolvimento Local Sustentável. Revista de Saberes (CETEAD/CIRIEC), n.0, p. 51-76.

BALESTRIN, A.; VARGAS, L. M. 2004. A dimensão estratégica das redes horizontais de PMEs: teorizações e evidencias. Revista de Administração Contemporânea, v. 8, ed. especial, p. 203-227.

BEGNIS, H. S. M.; PEDROZO, E. A.; ESTIVALETE, V. F. B. 2005. Cooperação enquanto estratégia segundo diferentes perspectives teóricas; Encontro da Associação Nacional de Pós-Graduação e Pesquisa em Administração (EnANPAD): EnANPAD -Encontro Nacional de Associações de Programas de Pós-graduação em Administração.

BENI, M. C. 2004. Globalização do Turismo - megatendências do setor e a realidade brasileira. 2. ed. São Paulo: Aleph.

BRUSCO, S.; E. RIGHI. 1989. Local government, industrial policy and social consensus: the case of Modena (Italy). Economy and Society, vol.18, n. ${ }^{\circ}$ 4, p. 405-24.

CASTELLS, M. 1999. A Sociedade em Rede. $2^{\mathrm{a}}$ ed., São Paulo: Paz e Terra.

COYNE, K.P. 1986. Sustainable Competitive Advantage - What It Is, What It Isn't. Business Horizons, p. 54-61, jan./feb.

COSTA, H. A. 2005. Contribuição das redes de pequenas e médias empresas para a competitividade de destinações turísticas: estudo comparativo entre Laguna e São Francisco do Sul-SC. Dissertação de Mestrado em Turismo e Hotelaria. Universidade do Vale do Itajaí. Balneário Camboriú.

EBERS, M.; JARILLO, J. C. 1998. The Construction, Forms, and Consequences of Industry Networks. Int. Studies of Management \& Organizations, vol. 27, n. ${ }^{\circ}$ 4, p. 3-21, winter.

FERNANDES, L. S. C. 2005. Arranjo Produtivo de Jóias e Folheados de Juazeiro do Norte: uma aposta que vale ouro. Monografia em Ciências Econômicas. Universidade Federal do Ceará. Fortaleza.

FILOS, E.; BANAHAN, E. 2000. Will the Organisation Disappear? The Challenges of the New Economy and Future Perspectives. In Camarinha-Matos, Afsarmanesh, Rabelo (eds): EBusiness \& Virtual Enterprises, Dordrecht: Kluwer, p.3-20.

GULATI, R.; NOHRIA, N.; ZAHEER, A. 2000. Strategic Networks. Strategic Management Journal. vol. 21, p. 203-215.

HALL, C. M. 2001. Planejamento Turístico: políticas (...). São Paulo: Contexto.

HOFFMANN, V. E. 2002. Los Factores Competitivos de la Empresa a partir de la Perspectiva de los Distritos Industriales: uno estudo de la industria de cerámica de revestimiento brasileña. España. Tesis Doctoral, Universidad de Zaragoza.

; MOLINA MORALES, Francesc Xavier. 2004. Redes de empresas: um estudo de competitividade em dois distritos industriais brasileiros. III Encontro de Estudos Organizacionais EnEO. Anais... Atibaia.

; ANDRIGHI F.; ANDRADE, M. A. R. 2008. Análise da Produção Científica no Campo de Estudo das Redes em Periódicos Nacionais e Internacionais. Texto em avaliação em periódico.

IBGE - Instituto Brasileiro de Geografia e Estatística. s/d. Cidades. Disponível em: $<$ http://www.ibge.gov.br/cidadesat/default.php>. Acesso em 14 de abril de 2007.

JARILLO, J. C. 1988. On Strategic Networks. Strategic Management Journal, vol. 9, p. 31-41. 
KNORRINGA, P.; MEYER-STAMER, J. 1998. New dimensions in local enterprise cooperation and development: from clusters to industrial districts. In UNCTAD (org.). New approaches to science and technology co-operation and capacity building. (ATAS Bulletin XI). New York, Geneve: United Nations, November.

LASTRES, H. M. M.; CASSIOLATO, J. E. 2003. Novas políticas na Era do Conhecimento: o foco em arranjos produtivos e inovativos locais. Revista Parcerias Estratégicas, n.17, p. 05-29, setembro.

LORENZONI, G.; ORNATI, O. 1988. Constellations of Firms and New Ventures. Journal ofBusiness Venturing. vol. 3, p. 41-57.

MARSHALL, A. 1925. A. Principles of Economics. 8 ed., London: Macmillan.

MEYER-STAMER, J. 1999. Estimular o crescimento e aumentar a competitividade no Brasil: Além da política industrial e da terceirização da culpa. Policy Paper, n. ${ }^{\circ}$ 23, janeiro de 1999. Disponível em $<$ http://www.meyer-stamer.de $>$. Acesso em 05 de março de 2006.

MOTTIAR, Z.; TUCKER, H. 2007. Webs of Power: multiple ownership in tourism destinations. Current issues in tourism, v. 10, n. 4, p. 279-817.

NORDIN, S. 2003. Tourism clustering and Innovation: (...). European Tourism Research Institute. Disponível em: $<\mathrm{http}: / /$ www.etour.com>. Acesso em janeiro de 2005.

O'CONNOR, Peter. 2001. Distribuição da Informação Eletrônica em Turismo e Hotelaria. Porto Alegre: Bookman.

PAVLOVICH, K. 2003. The Evolution and Transformation of a Tourism Destination Network: the Waitomo Caves, New Zealand. Tourism Management, vol. 24, p. 203-216.

PYKE, F., BECATTINI, G., SENGENBERGER, W. (eds.). 1990. Industrial districts and inter-firm cooperation in Italy. International Institute for Labour Studies.

PORTER, M. E. 1992. Vantagem Competitiva. Rio de Janeiro: Campus.

1999. Competição = (...): estratégias competitivas essenciais. $5^{\text {a }}$. Ed. Rio de Janeiro: Campus.

POWELL, W. W. H. 1990. Neither Market nor Hierarchy: networks forms of organizatiom. Research of Organizational Behaviour, vol.12, p. 295-336.

SANTUR - Órgão Oficial de Turismo do Estado de Santa Catarina. 2005. Perfil da Demanda Turística de Santa Catarina 2005. Disponível em <http://www.santur.sc.gov.br >. Acesso em 05 de março de 2006.

SAXENIAN, A. 1995. Lessons from Silicon Valley. Technology Review, v. 97, n. 5, Jul.

SCHOMMER, P. C. 2001. Gestão de Organizações Sem Fins Lucrativos: Algumas Questões sobre as "Especificidades" do Campo e o Perfil dos Gestores. Congresso Nacional das APAES. Anais...Federação Nacional das APAEs. Fortaleza, p. 273-278.

SCHUCH, C. H. 2001. Desempenho da Cadeia Produtiva na Indústria do Turismo (capítulo 2). In BARRATTO, Magarida; REJOWSKI, Mirian (orgs.). Turismo: interfaces, desafios e incertezas. Caxias do Sul: EDUCS, Coleção Turismo.

SECRETARIA MUNICIPAL DA INDÚSTRIA, COMÉRCIO E TURISMO DE URUBICI. 2006; 2007. Entrevista concedida pela secretária em exercício Sra. Ana Zilli, por meio eletrônico. Urubici.

SENGENBERGER, W.; PYKE F. 1992. Industrial Districts and Local Economic Regeneration: Research and Policy Issues. In PYKE, F.; SENGENBERGER, W. (ed.), Industrial Districts and Local Economic Regeneration, Genf: ILO. 
SILVA, C. M.; SCHROEDER, L.; HOFFMANN, V. E. 2004. As relações interorganizacionais como mecanismos de desenvolvimento. Anais do I Seminário de Gestão de Negócios da UniFAE. Curitiba, outubro/2004. Disponível em http://www.fae.edu/publicacoes/se1_artigos.asp>. Acesso em 06 de julho de 2007.

SWARBROOKE, J. 2000. Turismo Sustentável: setor público e cenários geográficos. vol. 3, 2ª ed. São Paulo: Aleph.

TREMBLAY, P. 1998. The Economic Organization of Tourism. Annals of Tourism Research, vol. 25, n. 4 , p. $837-859$.

THORELLI, Hans B. 1986. Networks: Between markets (...). Strategic Management Jornal, vol. 7.

VALE, G. M. V. 2004. Empreendedores Coletivos em Redes Organizacionais - novos agentes gerando um padrão diferenciado de competitividade. XXVIII EnANPAD - Encontro nacional dos programas de pós-graduação em administração. Anais... Curitiba.

VASQUEZ-BARQUERO, A. 2002. Desenvolvimento endógeno em tempos de globalização. Porto Alegre: UFRGS/FEE.

VERSCHOORE FILHO, J. R. S. 2003. O Programa Redes de Cooperação: (...). Anais do VIII Congreso Internacional del CLAD sobre la Reforma del Estado y de la Administración Pública, Panamá, p. 28-31, Out.

WEGNER D.; DAHMER, L. V. 2004. Avaliação de Desempenho em Redes de Empresas. XXIV ENEGEP - Encontro Nacional de Engenharia de Produção. Anais... Florianópolis.

WITTMANN, M. L.; NEGRINI, F.; VENTUTINI, T. 2003. As Redes Empresariais como uma Alternativa para Aumentar a Competitividade de Empresas do Setor de Comércio Varejista. XXVII ANPAD - Encontro nacional dos programas de pós-graduação em administração. Anais.... Atibaia.

WILLIAMSON, O.E. 1991. Comparative Economic Organization: the Analysis of Discrete Alternatives. Administrative Science Quarterly, v. 36, p. 269-296.

WOITCHUNAS, L. F.; SAUSEN, J. O. 2005. Fatores Críticos de Sucesso no Processo de Formação, Desenvolvimento e Manutenção de Redes de Cooperação e Suas Relações com o Desenvolvimento Local e Regional. XXIX EnANPAD - Encontro Nacional de Pós-Graduação e Pesquisa em Administração. Anais... Brasília.

Recebido em: 12/04/2009

Aprovado: 27/07/2009 